\title{
Does Pre-Test Accelerate Learning Pattern In Undergraduate Medical Students? A Prospective Study in a Tertiary Care Teaching Hospital in Tamilnadu
}

\author{
Akila Lakshmikandhan*1, Balaji Ramraj², Jamuna Rani Ravinder ${ }^{3}$ \\ ${ }^{1}$ Associate Professor, Department of Pharmacology, SRM Medical College Hospital and Research Centre, Kattankulathur, \\ Kancheepuram district, Tamilnadu, INDIA. \\ ${ }^{2}$ Associate Professor, Department of Community medicine, SRM medical college Hospital \& Research Centre, Kattankulathur, \\ Kancheepuram, Tamil Nadu, INDIA. \\ ${ }^{3}$ Professor \& Head, Department of Pharmacology, SRM Medical College Hospital and Research Centre, Kattankulathur, \\ Kancheepuram, Tamilnadu, INDIA.
}

\begin{abstract}
Objectives: Our objective was to asses if pre-test accelerates learning pattern in undergraduate medical students. Materials and Methods: A prospective study was conducted by the Department of Pharmacology at SRM Medical College Hospital and Research Centre, Kancheepuram district, Tamilnadu. A total of 121 II $^{\text {nd }}$ year MBBS students were divided into $A$ and $B$ batches with $61 \& 60$ students respectively. Objective type questions were prepared from the chapter "Haematinics" and were validated which contained extended match questions. B batch students were informed about the theory class topic the next day which will be preceded by a pre test and a post test at the end of the lecture. They were even given a copy of the topics from which questions were framed. A batch students were unaware about this plan of having pre and post tests the following theory class. On the day of lecture, all the students were given pre-test questions (total no: 20). The answer sheets were collected at the end of specified time period and evaluated. At the end of the lecture class, post test was conducted. Marks were tabulated with a maximum score of 20. Statistical analysis: Paired $t$-test was used to analyze the data obtained. Mean, Standard deviation and standard error of mean were calculated by feeding the data in SpSS software. Results: Both A and B batches have performed well in post-test than pre-test. $p<0.001$. Girls have scored more than boys in pre and post test. $p<0.001$. Discussion \& Conclusion: Pretest and post-test way of evaluating students is an effective \& feasible way of fun learning. The method of assessment using pre and post test questionnaire should be made mandatory in all medical schools/colleges after every theory class.
\end{abstract}

Key words: Pre-Test, Post Test, Pharmacology, Haematinics, Medical Education.

Citation: Lakshmikandhan A, Ramraj B, Ravinder JR. Does Pre-Test Accelerate Learning Pattern In Undergraduate Medical Students? A Prospective Study in a Tertiary Care Teaching Hospital in Tamilnadu. Int J Pharmacol and Clin Sci. 2016;5(4):109-12.

\section{INTRODUCTION}

The Medical Council of India has laid the significance on interactive teaching-learning methodology. The Graduate Medical Education regulation, New Delhi, in the year 1997 stated that the extensive goal of the teaching of II MBBS students in pharmacology is to say over and over a balanced and logical basis of treatment modalities. ${ }^{[1]}$

Though medical teachers do not undergo formal training programmes to teach undergraduate and postgraduate
Received: 4-8-2016 Revised: 18-11-2016 Accepted: 27-12-2016

*Correspondence : Akila Lakshmikandhan,

Associate professor, Department of Pharmacology, SRM Medical College Hospital and Research Centre, Kattankulathur, Kancheepuram District, Tamilnadu, INDIA.

Phone no: +91 - 9444553565

E-mail: drakilasenthil@gmail.com

Conflict of interest: Nil ; Source of support : Nil

Copyright: ${ }^{\odot} 2016$ Journal. All rights reserved.

DOI : $10.5530 /$ ijpcs.5.4.3 
students during their study period, they often add innovative and interesting methods to make medical syllabus easy to follow by the students. From Chalk and board teaching, it has evolved into OHP (over-head projector) slides, power point presentation, micro teaching, integrated teaching patterns(horizontal and vertical), Case scenario based learning $^{[2]}$ fishbowl strategy-based pharmacology teaching ${ }^{[3]}$ and the list is growing. Even while teaching practical's OSCE (Objective structured clinical examination) ${ }^{[4]}$ and OSPE (Objective structures practical examination) ${ }^{[5,6]}$ are used rather than long clinical cases and short cases alone. Nonetheless there is a growing demand for simple, quick, staff sparring, provocative, time sparring and cost effective methods to facilitate learning and to assess the process of student's knowledge.

Each method has its own limitations like time consumption and requirement of more faculty. Our objective was to assess if pre-test accelerates learning pattern in undergraduate medical students.

\section{MATERIALS AND METHODS}

A prospective study was conducted by the Department of Pharmacology at SRM Medical College Hospital and Research Centre, Kancheepuram district, Tamilnadu. It was carried out during the scheduled lecture class and practical class.

The study population included 121 second MBBS students belonging to 2014 batch admitted in SRM Medical College. They were divided into A and B batches with 61 \& 60 students respectively. Objective type questions in the form of "extended match questions" from the chapter "Haematinics" were prepared by eminent faculty in the Department of Pharmacology. The questions and answers were validated by the Professor and Head of the Department of Pharmacology. A day prior to the scheduled date of lecture class the pre test questions were handed over to B batch students during the practical hour. The students were asked to find out the answers for the same when they would come next day. A-batch students were unaware about this pre test questions. On the day of lecture, all the students were given pre-test questions (total no: 20). 105 students who were present on that day participated in the study. The lecture on Haematinics was taken by a faculty. The time allotted for both pre and post test was ten minutes. The answer sheets were collected at the end of specified time period and evaluated. Marks were tabulated with a maximum score of 20 .

\section{STATISTICAL ANALYSIS}

Paired $t$-test was used to analyze the data obtained. Mean. Standard deviation and standard error of mean were calculated by feeding the data in SpSS software.

\section{RESULTS AND DISCUSSION}

Among 121 students only 105 participated in the study. Among which 50 were boys and 55 were girls. All the students completed the test within the specified time. From Tables $1 \& 2$, it was seen that both A and B batches had performed well in post-test than pre-test. It was also noted that girls had answered better than boys in both the tests. Overall change in marks was seen in Table 2. Post test marks were almost the same in both $\mathrm{A}$ and $\mathrm{B}$ batches. Change in marks was high in girls than boys which was very evident from Tables $1 \& 2$. Medical educators are keenly looking for alternatives to didactic lectures. Because medical curriculum is vast and volatile it is essential to teach as well revise in a welcoming manner. Pre-test and posttest in a new chapter will tell a student "where he or she stands". Comparing both the marks also hints the teachers about the grasping and retaining power of students. From this we can easily identify the top performer of a class and also slow learners. Accordingly we can plan further corrections in teaching methodology. For instance to those who have got high marks in pre-test itself we can train them

\begin{tabular}{|c|c|c|c|c|}
\hline & Pre test & Post test & Paired $\mathrm{T}$ test & $P$ value \\
\hline $\begin{array}{c}\text { All } \\
\text { students }\end{array}$ & $7.50 \pm 0.37$ & $15.01 \pm 0.32$ & -17.614 & 0.0001 \\
\hline A batch & $7.14 \pm 0.50$ & $15.63 \pm 0.43$ & -13.894 & 0.0001 \\
\hline B batch & $7.92 \pm 0.54$ & $14.31 \pm 0.46$ & -11.548 & 0.0001 \\
\hline Girls & $8.42 \pm 0.55$ & $16.09 \pm 0.36$ & -13.343 & 0.0001 \\
\hline Boys & $6.50 \pm 0.44$ & $13.82 \pm 0.49$ & -11.476 & 0.0001 \\
\hline
\end{tabular}

$\begin{array}{lcccc}\begin{array}{l}\text { Table 2: Difference in the marks obtained between the } \\ \text { groups. } \\ \text { Period }\end{array} & \text { Batch } & \text { Un Paired T test } & \text { P value } & \\ & \text { A Batch } & \text { B Batch } & & \\ \text { Pre test } & 7.14 \pm 0.50 & 7.92 \pm 0.54 & -1.054 & 0.295 \\ \text { Post test } & 15.63 \pm 0.43 & 14.31 \pm 0.46 & 2.088 & 0.039 \\ & \text { Gender } & & & \\ & \text { Girls } & \text { Boys } & & \\ \text { Pre test } & 8.42 \pm 0.55 & 6.50 \pm 0.44 & 2.684 & 0.008 \\ \text { Post test } & 16.09 \pm 0.36 & 13.82 \pm 0.49 & 3.760 & 0.0001\end{array}$


more pharmacology in depth including the experimental pharmacology till recent advance. Rather a student with learning difficulty can be approached about his or her preferred mode of learning like visual or auditory methods.

This study was designed to judge the effect of pre and post test in accelerating learning pattern. Assessment reports had shown clearly that students achieved high marks in post test (Table 1). Thus pre-test and post test evaluation had got overwhelming response from the students which was very evident from their feedback forms.

Recent studies by Sunil Nettath in 2014, using Computer assisted learning (CAL) as a teaching learning method, confirmed the improvement in student's performance in posttest. ${ }^{[7]}$ Arun Mehnaatamai Mohanram et al in April 2015 evaluated the effectiveness of Pretest and Posttest Model of Active Learning in a Medical School which again proved that this is an efficient and feasible way of assessing students. ${ }^{[8]}$ Padmanabha TS et al, in 2016 have said that we should sensitize even more early in II phase of MBBS by educational intercession, which will enhance the active contribution of students. ${ }^{[9]}$

In the current study though the B-batch students were aware of the assessment the next day, their pre and post test marks were not significantly different from that of A-batch. The probable reasons could be either presence of more of intellectual students in A-batch or B-batch students did not take it seriously as they have never written such tests in the past.

The study by Manjunath SM et al revealed the perception and feedback of the students regarding learning pharmacology and revealed the priority areas for improvement. It is important to know what our students need and whether they feel comfortable with the ever expanding course and limited duration of time. ${ }^{[10]}$ Regular feedbacks may help teachers to plan the curriculum and improve the teaching for undergraduate students. Mandia J et al recently in 2016 had supported this study stating that teachers also could improve their ability to learn and skills in imparting medical education. ${ }^{[11]}$ Even the most recent study by Jag tap et al has stated that applying pre test and post test was very useful not just in evaluating the performance of one subject but in integrated teaching of medical syllabus..$^{[12]}$

\section{CONCLUSION}

Pre test and post test way of evaluating students is an effective $\&$ feasible way of fun learning with less utilization of resources, saves paper, so environment friendly, time sparring and a simpler tool to assess. The method of assessment using pre and post test questionnaire should be made mandatory in all medical schools/colleges so that students will welcome this way of appraisal.

\section{FUTURE SUGGESTIONS OF THE STUDY}

There is no negative marking in this assessment. So the marks obtained may give false positive results. Serial number of the questions may be changed to avoid malpractice if any. More questions in the form of fill up the blanks can be asked. It may be presented in the form of a mixture of extended match questions, fill up the blanks, picture based questions, multiple true/false and problem based learning.

Instead of conducting internal assessment tests in the form of essays, short notes and conventional multiple choice questions we can rather organize similar assessments as mandatory. So that students will become more serious, more attentive, try to listen, understand and if they don't understand a portion, they may come forward to clarify their doubts.

\section{ACKNOWLEDGEMENT}

1. We sincerely thank our Dean, Dr A.Sundaram, for his constant support in our academic activities.

2. We acknowledge II MBBS students (120+34) of 2014 batch who actively took part in our study.

\section{CONFLICT OF INTEREST}

None

\section{ABBREVIATION USED}

SPSS: Statistical package for Social sciences; CAL: Computer assisted learning; OHP: over-head projector; OSCE: Objective structured clinical examination; OSPE: Objective structures practical examination.

\section{REFERENCES}

1. Salient features of Regulations on Graduate Medical Education, 1997 (Internet). 1997. Published in part iii, section 4 of the Gazette of India dated $17^{\text {th }}$ May 1997.Regulations/raduate Medical Education Regulations. 1997.aspx. Accessed 20 February 2016. 
2. Walke YS, Rataboli PV. Introduction of the role play: An effective innovation in medical education technology. Pharmacology Online. $2011 ; 31234-41$

3. Mutalik MM. Student perceptions and learning outcome on a "fishbowl" strategy-based pharmacology seminar on drug dependence. International Journal of Basic \& Clinical Pharmacology. 2016;5(3):879-83. doi:10.18203/2319-2003. ijbcp20161539.

4. De VT. Presenting clinical pharmacology and therapeutics: the course in pharmacotherapeutics. British Journal of Clinical Pharmacology. 1993;35(6):587-90.

5. Batmanabane $\mathrm{GI}$, Ravendran R, Shashindran $\mathrm{CH}$. Objective structured practical examination in pharmacology for medical laboratory technicians. Indian Journal of Physiology and Pharmacology. 1999;43:242-6.

6. Malhotra SD, Shah KN, Patel VJ. Objective structured practical examination as a tool for the formative assessment of practical skills of undergraduate students in pharmacology. Journal of Education and Health Promotion. 2013;2:53. doi:10.4103/22779531.119040.

7. Nettath S. Computer assisted learning (CAL) as a teaching learning method in teaching experimental pharmacology. Int $\mathrm{J}$
Basic Clin Pharmacol. 2014;3(1):63-65. doi:10.5455/2319-2003. ijbcp20140204.

8. Mohanram AM, Zhong Q, Singh T, Jagadeesh A. Evaluating the Effectiveness of Pretest and Posttest Model of Active Learning in a Medical School. The FASEB Journal. 2015;29(1 Supplement):928-4.

9. Padmanabha TS, Manu G, Savkar MK, Chandrakantha T, Neha K. Student's perception towards learning medical sciences: problem based learning versus lecture based learning methods. International Journal of Basic \& Clinical Pharmacology. 2016;5(2):411-5. doi:10.18203/2319-2003.ijbcp20160754.

10. Manjunath SM, Nagesh RG, Srinivas TR, Someswara GM. A study on the evaluation of medical student's perception and feedback of teaching-learning of pharmacology in a medical college.

11. Mandla J, Shaik H, Pidigundla D, Katepogu V. Evaluation of lectures by pre \& post-test MCQS. Journal of Education Technology in Health Sciences. 2016;3(2):65-7.

12. Jagtap RP, Sayyed HA, Tiwari SA, Daswani BR, Dabhade SS, Ghongane BB. Study of Impact of Interdisciplinary Seminar as an Integrated Teaching - Learning Innovation in M.B.B.S Students. JMSCR. 2017;(3):19334-40. 